\title{
VIOLÊNCIA DE GÊNERO E LAWFARE: UMA ANÁLISE DOS CASOS DILMA ROUSSEFF E CRISTINA FERNÁNDEZ DE KIRCHNER
}

\author{
Gender violence and lawfare: an analysis of judicial persecution against \\ Dilma Rousseff and Cristina Fernández de Kirchner
}

Indiana Rocío Azar

Luiza Tavares da Motta

Resumo: $\mathrm{O}$ artigo pretende analisar o processo judicial contra a ex-presidenta Cristina Fernandez de Kirchner na Argentina, e o impeachment da ex-presidenta Dilma Rousseff no Brasil, a partir de um ponto de vista que leva em consideração o fato de se tratar de mulheres que ocuparam o mais alto posto do Poder Executivo. Trata-se, a partir de pesquisa bibliográfica, da ameaça que o populismo e o ativismo do Poder Judiciário representam para a democracia. O conceito de lawfare vem, neste trabalho, como primeiro eixo pelo qual se desenvolverá o estudo entre os casos da Argentina e do Brasil: lanfare como a utilização do judiciário para impor rumos ao processo político. Assim, empreende-se estudo em que se aponta o emprego do lanfare na persecução judicial da ex-presidenta argentina Cristina Fernández de Kirchner e da ex-presidenta brasileira Dilma Rousseff. A violência de gênero que se manifestou quando o lanfare se voltou contra mulheres é o segundo eixo em torno do qual se desenvolve o trabalho. A articulação das duas lentes apresentadas permitiu perceber que o sexismo e os estereótipos de gênero trabalham como reforço em apelo ao apoio popular, quando os institutos jurídicos são manipulados em prol dos interesses de instâncias do poder.

Palavras-chave: Lanfare. Violência de gênero. Cristina Fernandez Kirchner. Dilma Rousseff.

Abstract: This work intends to analyze the judicial prosecution of ex-president Cristina Fernández de Kirchner in Argentina, as well as the impeachment of ex-president Dilma Rousseff in Brazil, from a point of view that takes into consideration the fact that they are both women who have occupied the highest place in the Executive Power. This bibliographical research tackles the menace that populism and activism in the Judiciary Power represent to democracy. The concept of lawfare is shown in this work as the first axis from which the comparison between the cases of Argentina and Brazil: lanfare as the use of the judiciary system to impose conclusions to the political process. This study points out the use of lanfare in judicial persecution of Argentine ex-president Cristina Fernández de Kirchner and Brazilian ex-president Dilma Rousseff. The gender violence that manifested itself when lawfare turned against women is the second axis from which the research is developed. The use of these two lenses of analysis has allowed the researchers to point out the sexism and that gender stereotypes reinforce, with popular support, the manipulation of judicial institutes by the powerful sections of society.

Keywords: Lawfare. Gender violence. Cristina Fernandez Kirchner. Dilma Rousseff.

Artigo recebido em 9 jul. 2019 e aprovado em 2 ago. 2019. 


\section{Introdução}

Lawfare, enquanto contração das palavras "law" (lei) e "warfare" (guerra), serve para indicar o mecanismo de guerra judicial em que o ordenamento jurídico é manipulado de forma a causar efeitos operacionais, no mais das vezes, antidemocráticos. Este artigo, ao analisar os casos do impeachment da ex-presidenta brasileira Dilma Rousseff e da persecução judicial da ex-presidenta argentina Cristina Fernández de Kirchner, aponta as semelhanças na questão de fundo dos processos que se desenrolaram, a partir de uma ótica que leva em consideração a posição das duas figuras políticas como mulheres.

É certo que a participação da mulher na política e na vida pública encontrou e ainda encontra diversos óbices, formais ou materiais. A luta das mulheres pelo direito de votar e serem votadas, vinda desde o século XIX (MIGUEL, 2014, p. 93-107), ainda não superou as barreiras da desigualdade material na representação política, embora diferenças marcantes possam ser observadas, dependendo do caso. Por exemplo: em 2019, no Brasil, as mulheres que compõem a Câmara dos Deputados são 15\% do total de membros, enquanto que, no Senado Federal, elas representam 13\% dos eleitos (TRIBUNAL SUPERIOR ELEITORAL, 2019).

Atualmente, no caso argentino, a Câmara dos Deputados conta com 99 mulheres, representando 38,5\% do total, enquanto o Senado é atualmente composto por 30 mulheres, o que equivale a uma participação de 41,6\% do total (OBSERVATÓRIO POLÍTICO ELEITORAL, 2019).

Neste contexto, as eleições das presidentas Dilma Rousseff, no Brasil, e Cristina Fernández de Kirchner, na Argentina, representaram - ou pareceram representar - um grande passo na luta por maior representação das mulheres na política. Elas quebraram os estereótipos marcados em relação à mulher em posições de liderança, ao mesmo tempo em que mudaram o próprio idioma: tanto foi o estranhamento que, ao intitularem-se "presidentas", as duas ex-chefes do poder executivo levantaram discussões pelo Brasil e pela Argentina.

Ao analisar os casos da ex-presidenta Cristina Fernández de Kirchner e da ex-presidenta Dilma, ambas as lentes apresentadas darão escopo para a comparação entre os casos brasileiro e argentino de persecução judicial de mulheres que assumiram a presidência de modo a demonstrar a violência de gênero que se apresentou quando o lawfare se voltou contra elas. 
Deste modo, o artigo tratará, em seu primeiro capítulo, do conceito de lawfare e da aplicação de mecanismos judiciais para fins políticos, fato que tem sido cada vez mais largamente observado no contexto latino-americano. Passará, então, a apresentar estudo da representação feminina na política dos dois países aqui tratados, com o objetivo de demonstrar os obstáculos ainda encontrados pelas mulheres para assumir cargos eletivos e durante o exercício de seus mandatos. As trajetórias dos processos que se desenvolveram contra Dilma Rousseff e Cristina Fernández de Kirchner serão tratadas separadamente, para, então, apresentar as conclusões acerca dos pontos de encontro entre os dois casos, nos quais se poderá ver a forma como a violência de gênero se apresenta como fator quando mulheres na política sofrem ataques judiciais com escopo político típico do lawfare.

\section{Lawfare na América Latina}

O termo lawfare, cunhado inicialmente para designar o uso do Direito como arma de guerra - para atingir, portanto, fins militares (DUNLAP JUNIOR, 2008, p. 146-154) - passou a ser disseminado e diluído para passar a significar também o uso do Direito como arma para atingir fins políticos, embora não haja unanimidade na doutrina em relação à natureza benéfica ou maléfica do instituto.

Se, por um lado, diversos autores conceituam o lanfare como o mau uso do Direito para manipular decisões e resultados na esfera política (CARLSON e YEOMANS, 1975), há aqueles que defendem o lawfare como técnica de judicialização de questões políticas, de modo que poderia ser utilizado em defesa das minorias (COMAROFF e COMAROFF, 2006).

O segundo grupo, no entanto, parece trazer uma visão um tanto otimista do Poder Judiciário e seus compromissos, segundo conclui George E. Bisharat (2017, p. 296-308) ao tratar do lawfare no caso Israel/Palestina, em que os palestinos passaram a demandar mais direitos na justiça, e, logo, o judiciário voltou-se contra eles quando grupos como Shurat Hadin ("letra da lei”) passaram a combater, por meio de diversos processos judiciais, o que eles intitulavam lawfare dos palestinos, quando demandavam por direitos humanos: o slogan do grupo era "Falindo o terrorismo, um processo por vez". Sobre o caso Israel/Palestina, conclui o autor : "Nosso erro foi confiar em um direito desconectado da política - imaginar que a lei poderia compensar a desvantagem política. O que estamos aprendendo agora é que 
não há atalhos para aqueles que não tem poder - a lei não será nosso refúgio" (BISHARAT, 2017, p. 296-308).

Neste trabalho, tratar-se-á lawfare como a manipulação dos institutos jurídicos para levar a disputa política para além das urnas eleitorais. Deste modo, o conceito de lanfare aqui não diz respeito à judicialização de questões políticas lato sensu, mas à manipulação de institutos jurídicos e do próprio judiciário para a obtenção de resultados na esfera política.

Neste sentido, o lawfare aparece aqui como prática antidemocrática de ativismo judicial: o judiciário, hipertrofiado, passa a agir contra a Constituição e os institutos democráticos em nome de um discurso moralista fundado em uma demanda de aprovação pela opinião pública - em nome, mesmo, de um populismo (SALGADO, 2018, p. 193-217) que jamais poderia fazer parte do Poder Judiciário por ser contra sua própria constituição. Ainda nesta esteira, alerta a Professora Eneida Desiree Salgado:

O ativismo judicial para além dos limites constitucionais com fundamento em argumentações extrajurídicas sugere que o messianismo e o populismo se deslocaram na estrutura estatal. Se o medo do discurso moral, contrário à Constituição, vinha relacionado com o agir do Poder Executivo e, de maneira mais fraca, do Poder Legislativo e dos partidos políticos, agora a preocupação é com os salvadores da pátria togados. (SALGADO, 2018, p. 212)

Nos últimos anos, esse processo de criminalização e perseguição de governos e frentes políticos progressistas e populares foi desencadeado na América Latina. Para que tal prática seja possível, “[...] requer não apenas juízes cúmplices, mas também meios de comunicação de massa que agem em coordenação com esses objetivos" (MORENO, 2018, p. 389, tradução nossa). Existem diferentes exemplos no continente: na Argentina, a perseguição judicial da ex-presidenta Cristina Fernández de Kirchner e a intervenção judicial do Partido Justicialista (2018); no Brasil, a presidenta Dilma Rousseff (2016) e a prisão irregular do ex-presidente Luiz Inácio Lula da Silva (2018); no Equador, a perseguição judicial do ex-chefe de Estado, Rafael Correa (2018); no Paraguai, a demissão de Fernando Lugo (2012); e em Honduras, a demissão de Manuel Zelaya (2016).

O lawfare no Brasil se fez claro com a atuação dos magistrados na Lava Jato: a promoção de escândalos políticos em torno da ex-Presidenta da 
República Dilma Rousseff pelo próprio juiz encarregado da operação - refere-se aqui ao vazamento à imprensa de gravação de escuta telefônica cuja interrupção já se havia determinado no processo de origem - é apenas um exemplo das inconstitucionalidades e ilegalidades que se vem perpetrando em função de objetivos políticos. A nomeação do juiz Sérgio Moro ao Ministério da Justiça pelo candidato da oposição, cuja campanha presidencial se fez sobre as alegações de corrupção do Partido dos Trabalhadores, não deixa dúvidas sobre a natureza dos escândalos políticos, como a sentença que determinou a prisão do ex-presidente Luiz Inácio Lula da Silva sem qualquer prova que sustentasse a condenação (SIQUEIRA NETO, 2017, p. 223-227), e a já comentada liberação inconstitucional de gravação da ex-presidenta Dilma Rousseff aos meios de comunicação.

\section{Mulheres na política: desafios entre Brasil e Argentina}

Historicamente, as mulheres têm sido confinadas ao espaço privado. A Revolução Francesa, que inspirou muitos dos atuais modelos de Estado, inclusive o Brasileiro, terminou com o afastamento das mulheres do espaço público: a filosofia iluminista, para o Professor Xavier Martin, historiador do direito e professor na Université d'Angèrs, explica-se pela própria filosofia iluminista da época: em seu artigo intitulado "Misogynie des rédacteurs du Code civil: une tentative d'explication” (2005, p. 69-89), explica e explicita toda uma filosofia que girava em torno, com bases pretensamente científicas, de uma fragilidade feminina que a incapacitava para a vida civil. Para os pós-revolucionários, portanto, a mulher, dotada de fibras menos fortes e nervos mais frágeis que os dos homens, sentia e sofria muito mais fortemente as impressões dos sentimentos, tornando-a, deste modo, incapaz de um pensamento racional.

Explica-se: o racionalismo francês tomava o pensamento como complexificação do sentimento - o pensar nada mais era que um sentir aprofundado. Se, portanto, explica Martin, as mulheres tomam em seus nervos impressões mais profundas do sentir, sentem mais, e, ainda, sentem ao mesmo tempo tudo que se passa, são incapazes de evoluir do sentir ao pensar. Deste modo, são seres muito mais próximos do homem natural que do cidadão: não têm senso de planejamento futuro, de racionalização, e eram acusadas, ainda, de trazerem algo de anarquia, algo de desordem, algo a ser expurgado da vida pública (MARTIN, 2005). 
Já foi mencionado que, no Brasil, o voto feminino foi regulamentado apenas durante a década de 30. A participação das mulheres na política brasileira, desde então, cresceu muito pouco, mesmo com os crescentes debates e ações afirmativas (LUCHTEMBERG, 2018), desde a IV Conferência Mundial da Mulher, em Pequim, 1995 (VIOTTI, 1995).

$\mathrm{Na}$ Argentina, embora possamos traçar, nas primeiras décadas do século XX, casos como Julieta Lantieri, que, como assinala Toppi (2016), foi a primeira mulher argentina e sul-americana a votar, em 1911, antes do estabelecimento do sufrágio masculino universal (Lei Saenz Peña, 1912), a extensão dos direitos políticos às mulheres ocorreu apenas em 1947, com a promulgação da Lei n⿳ 13.010. Desde esse momento, a participação das mulheres na arena política tem sido cada vez maior, o que é complementado por dois marcos que correspondem à promulgação de leis de cotas, a primeira de 1991 (Lei no 24.012), estabelecendo um piso mínimo de 30\% das mulheres em todas as listas, e a lei de 2017 (Lei nº 27.412), que estabelece a paridade nas listas eleitorais. Por sua vez, o Brasil também tem lei de cotas (Lei n⿳9 9540) desde 1997, que afirma que os partidos políticos devem se registrar pelo menos $30 \%$ de mulheres candidatas. Mais ainda, a sua presença na política continua atrasada.

Anne Phillips (1991) afirma não bastar a retirada das barreiras legais formais para que as mulheres se insiram na política. É preciso romper a inércia que as mantêm afastadas e colocá-las dentro do campo político. Luís Felipe Miguel (2014) aponta, como fatores importantes desse afastamento feminino da política, não apenas a ainda perpetrada noção geral de que a mulher não tem lugar ou aptidão para o espaço público, nem tão-somente sua suposta afinidade maior às tarefas domésticas, mas impossibilidade material: "O insulamento na vida doméstica retira delas a possibilidade de estabelecer a rede de contatos necessária para se lançar na carreira política. Aquelas que exercem trabalho remunerado permanecem em geral como responsáveis pelo lar, no fenômeno conhecido como 'dupla jornada de trabalho', tendo reduzido seu tempo para outras atividades, incluída aí a ação política.” (MIGUEL, 2014, p. 94).

Em consonância, outro elemento a ter em conta ao analisar a participação das mulheres nos espaços políticos é a percepção pública da liderança feminina, ou seja, a valorização da sociedade sobre as mulheres em cargos de responsabilidade. Conforme D'Adamo et al, ao longo do tempo, as mulheres em cargos políticos ganharam maior aceitação, mais ainda en- 
frentam outros obstáculos, como é o caso dos estereótipos de gênero: “[...] aquelas características que no abstrato consideram 'propriamente feminina' e orientam a formação de certas expectativas em torno do comportamento esperado das mulheres" (D’ADAMO et al., 2008, p. 92, tradução nossa). Quando os personagens femininos não correspondem aos "aspectos prescriptivos do estereótipo do gênero que lhes foi designado geralmente desperta condutas discriminatórias e hostis contra elas" (D'ADAMO et al., 2008, p. 92, tradução nossa).

Em comparação com o caso argentino, por exemplo, notam Silva e Santos que "enquanto no Brasil as mulheres representam 9,94\% das vagas obtidas na Câmara dos Deputados e 13,58\% no Senado nas últimas eleições (2014), na Argentina esses percentuais sobem para 36,58\% na Câmara dos Deputados e 38,89\% no Senado (eleições 2013)" (SILVA e SANTOS, 2015). Lúcia Avelar e Patrícia Rangel, ao realizarem comparação entre os casos argentino e brasileiro de representação de mulheres, concluem que, embora os processos de democratização em ambos os países tenham contado com uma forte participação feminina, e ambos tenham avançado muito desde a década de 1990 em termos de conquistas de direitos para as mulheres, caminharam em vias muito diversas (AVELAR e RANGEL, 2017): enquanto na Argentina a legitimação e os movimentos de representação dos interesses femininos se dão por vias eleitorais, no Brasil os locais de luta feminista se apresentam em vias extraparlamentares,9 "com inserção de feministas em órgãos estatais” (AVELAR e RANGEL, 2017, p. 299).

De fato, portanto, percebe-se que a representatividade das mulheres na política, tanto na Argentina quanto no Brasil, ainda não chegou à paridade em relação à representatividade masculina, embora a Argentina apresente dados mais favoráveis à participação das mulheres na vida pública.

\section{O Caso Dilma Rousseff}

Dilma Rousseff foi eleita a primeira presidenta do Brasil em 2010 e, embora ter uma mulher ocupando o cargo mais alto do poder executivo possa parecer uma abertura da política à participação feminina, as mulheres ainda ocupavam menos de 10\% das casas parlamentares (MENEZES, 2017).

A verdade é que mesmo a posição da presidenta foi contestada durante todo o seu governo pelos meios de comunicação que atribuíam 
sua vitória à popularidade do ex-presidente Luiz Inácio Lula da Silva, assim como atribuíam seus atos a mandos e desmandos vindos, supostamente, do próprio ex-presidente (CHATES, 2017). Mulher na presidência ou não, o fato é que o Brasil preferiu considerar estar sob o governo do ex-presidente Luiz Inácio Lula da Silva, ainda que sob o disfarce de Dilma Rousseff, que nada mais teria sido, em sua eleição, que herdeira do apelo popular do ex-presidente.

O crime de responsabilidade supostamente cometido pela presidenta foi o menor dos fatores para seu afastamento do cargo, conforme concluem Benevide, Passos e Silva: internacionalmente, a confirmação da viabilidade da extração do pré-sal despertou interesses importantes nos Estados Unidos; internamente, as políticas públicas promovidas pelo governo do Partido dos Trabalhadores passaram a incomodar uma parte da elite econômica (BENEVIDES, PASSOS e SILVA, 2017).

A natureza política do julgamento do processo de impeachment, que, segundo os autores recém mencionados, não pode estar desconectado de razões políticas das mais nobres às mais vis, tendo em vista ser realizado pela Câmara dos Deputados e pelo Senado Federal - e, portanto, não pelo poder Judiciário -, não significa permitir um total afastamento do processo de razões e limites constitucionais (BENEVIDES, PASSOS e SILVA, 2017): para que o processo de impeachment seja constitucional, é preciso que o ato cometido pelo ou pela ocupante do cargo de Presidente da República se enquadre nas descrições da Lei nº 1.079/50, e a ocorrência do delito de responsabilidade precisa ser comprovada (BENEVIDES, PASSOS e SILVA, 2017).

É neste sentido que se defende, no presente artigo, o enquadramento do processo de impeachment que se desenrolou contra a ex-presidenta Dilma Rousseff como exemplo de lawfare perpetrado pelos movimentos de direita: embora não envolvido diretamente o Poder Judiciário no referido processo, trata-se de procedimento previsto na Constituição Federal e cujo desenvolvimento deve atender aos requisitos do diploma mencionado, sob pena de ferir-se o Estado Democrático de Direito.

Ocorre, no entanto, que, no momento das críticas e da crise política pela qual passou o governo Dilma, sua condição de mulher teve uma relevância que não pode ser ignorada. Ao analisar a representação da presidenta em revistas de circulação semanal, de abril a setembro de 2016, as autoras Amanda Oliveira Rechetnicou e Viviane C. Vieira identificam a re- 
presentação de Dilma Rousseff a partir de estereótipos de gênero voltados a reforçar uma noção de que as mulheres são inaptas para a política muitas vezes pelas mesmas razões apontadas por Martin ao fazer uma retomada do afastamento da mulher do espaço público já quando da Revolução Francesa (MARTIN, 2005): a presidenta era retratada como "louca", "insana", "incapaz” de governar um país (RECHETNICOU e VIEIRA, 2017).

Neste sentido, concluem as autoras, pela análise realizada dos discursos apresentados, que "Esse modo de avaliar e identificar essa agente social teve efeitos potenciais na legitimação de posicionamentos pró-impeachment e, certamente, serviu à reprodução e naturalização de um discurso de ódio contra a então presidenta, o que favoreceu o golpe de 2016 que a afastou do governo" (RECHETNICOU e VIEIRA, 2017, p. 07).

Não se pretende dizer que a condição de mulher da ex-presidenta Dilma Rousseff tenha sido o fator único - nem mesmo o fator decisivo para seu afastamento do cargo. O que se nota, no entanto, é que sua condição de mulher desempenhou um papel importantíssimo na natureza das críticas a ela dirigidas, e o apelo da mídia, mais uma vez, à figura da mulher "irracional" e "incapaz" é a prova cabal de que a representatividade da mulher na política ainda tem muito a caminhar, e a caminhada não será livre de obstáculos.

\section{O caso Cristina Fernández de Kirchner}

Cristina Fernández de Kirchner (adiante referida como CFK) assumiu a presidência da República Argentina em dezembro de 2007, tornando-se, então, a primeira mulher eleita popularmente a alcançar o Poder Executivo Nacional.

Ao finalizar seu primeiro mandato, a presidenta se candidatou novamente à reeleição. Nas eleições de 2011, a chapa encabeçada por CFK logrou uma vitória com 54,11\% (DIRECCIÓN NACIONAL ELECTORAL DEL MINISTERIO DEL INTERIOR, OBRAS PÚBLICAS Y VIVIENDA, 2011) dos votos. A partir de 10 de dezembro de 2007, CFK sucedia seu marido, Néstor Kirchner, no cargo de Presidente, e, por esse motivo, sua chegada ao poder foi precedida de uma forte campanha midiática que fazia referência ao "matrimônio presidencial", e que advertia que o verdadeiro "homem forte" do governo continuava sendo o ex-presidente (PÉREZ e AYMÁ, 2017). 
É importante mencionar que a ex-presidenta sofreu perseguição da mídia desde que se tornou Primeira Dama e durante seus dois mandatos presidenciais, em particular imediatamente após a sanção da "Lei de Meios de Comunicação" (Lei no 26.522), que substituiu uma lei do período da última ditadura civil militar pela qual passara a Argentina. Tal norma dispunha sobre a "regulação dos serviços de comunicação audiovisual em todo o âmbito territorial da República Argentina e o desenvolvimento de mecanismos destinados à promoção, desconcentração e fomento da competência com fins de barateamento, democratização e universalização do aproveitamento das novas tecnologias da informação e da comunicação". A lei gerou um enfrentamento entre o governo e as corporações que monopolizavam os meios de comunicação, em especial com o Grupo Clarín, que reclamava a inconstitucionalidade da lei e opôs medida judicial sob esse fundamento (CENTRO DE INFORMACIÓN JUDICIAL, 2013).

$\mathrm{O}$ assédio midiático apresentou também outros aspectos, diversos daqueles econômicos e políticos. Por exemplo, a Revista Noticias, que, no decorrer dos anos, desenvolveu um discurso negativo acerca da figura de CFK, com um marcado tom sexista, o qual reproduzia os estereótipos de gênero a respeito das mulheres na política. Sobre isso, Pérez e Aymá (2017) apontam que os meios de comunicação empregam estratégias discursivas que objetificam e sexualizam a mulher, anulando-a como sujeito, e, portanto, como ator político.

Desta maneira, podemos observar no discurso hegemônico o dispêndio de dispositivos de neutralização, deslegitimação e normalização. Se desloca o foco do tratamento das questões políticas a questões de ordem privada. A aparência, a família, a maternidade, os sentimentos, a intimidade se convertem no centro da preocupação do discurso jornalístico quando se trata de mulheres. (PÉREZ e AYMÁ, 2017, p. 527, tradução nossa)

A ex-mandatária declarou, em seu livro recentemente publicado: "Las tapas de la Revista Noticias condensaron, a partir de 2006, los agravios más violentos y misóginos contra mí” (FERNÁNDEZ DE KIRCHNER, 2019 , p. 164). Menciona que as dissimulações que protagonizava na Revista Noticias a estigimatizaram e que foram parte de "ataques planificados y sistemtizados” (FERNÁNDEZ DE KIRCHNER, 2019, p. 164) contra seu governo. 
Em termos de perseguição judicial, desde o fim de seu primeiro mandato, CFK se viu acusada por diversos motivos (supostas irregularidades em seu patrimônio, evasão de impostos, negociações incompatíveis com a função pública, enriquecimento ilícito, entre outros), mas foi vencedora, e os processos judiciais foram arquivados ou encerrados, respectivamente. Não foi senão em 2014 que começaram as acusações de maior envergadura, entre as quais as causas "Hotesur", "Los Sauces", "Memorandun con Iran" e "Dólar Futuro". Uma explicação possível para isto é aquilo que Helmke e Wolfson denominam desafección estratégica: "Especificamente, quando um governo em exercício começa a perder poder e debilitar-se, os juízes carentes de segurança institucional se veem estimulados a incrementar suas medidas contrárias ao governo com o fim de distanciar-se deste" (HELMKE e WOLFSON, 2003, p. 179-201) (tradução nossa).

Coincidentemente, a partir de 2013, uma sucessão de acontecimentos faz minguar o poder simbólico do governo kirchenista. Nas eleições intermediárias do mesmo ano, perdeu-se a maioria que havia obtido. Ainda que tenha mantido o controle em ambas as casas do Congresso (DIRECCIÓN NACIONAL ELECTORAL, MINISTERIO DEL INTERIOR, OBRAS PÚBLICAS Y VIVIENDA, 2013), passou-se a depender da ajuda de seus aliados para os dois anos de governo que restavam a CFK. No mesmo ano, Sergio Massa rompe com a frente política e forma, junto a outros 13 prefeitos da Província de Buenos Aires, o "Frente Renovador", força que resultaria vencedora nesta Província, o distrito de maior magnitude do país. A partir desse momento, o panorama político mostrava que a Presidenta terminaria seu mandato sem um caminho político claro e sem possibilidades de reeleição, ao não contar com o número de legisladores que lhe permitiriam a reforma constitucional necessária para tanto.

Nas eleições presidenciais de 2015, a força liderada pela mandatária passou o primeiro turno, mas perdeu no segundo. A coalizão "Cambiemos", encabeçada por Mauricio Macri, obteve a vitória com 51,34\% dos votos (DIRECCIÓN NACIONAL ELECTORAL, MINISTERIO DEL INTERIOR, OBRAS PÚBLICAS Y VIVIENDA, 2015).

A partir de então, o assédio judicial aumentou paulatinamente. Em 2018, CFK se pronunciou a respeito, indicando explicitamente que se tratava de um processo de lawfare. Segundo ela: "me armaron seis causas penales y todas ellas fueron radicadas en Comodoro Py. De las seis, cinco fueron iniciadas e impulsadas por Bonadío. [...]” (CRISTINA..., 2018), e continuou dizendo que foi 
uma "[...] decisión política del Poder Judicial -en su más alta expresión- en coordinación con el Poder Ejecutivo y los medios hegemónicos [...]" (CRISTINA..., 2018).

Cabe mencionar que os meios de comunicação relembraram as causas que pesavam sobre CFK em momentos em que "Cambiemos" levava adiante medidas prejudiciais à sociedade (como o aumento das taxas de serviços ou transportes), ou ainda quando surgiam escândalos vinculados aos membros do governo, o que foi denunciado pelos meios opositores (CRISTINA..., 2019) ao governo macrista, bem como pela ex-presidenta (CRISTINA..., 2018). Não obstante, nenhuma das causas foi sentenciada definitivamente até o momento.

\section{Considerações finais}

O uso do lanfare como manobra política de perseguição judicial de lideranças progressistas na América Latina, demonstrado pelas provas inconclusivas contra as ex-presidentes, mas cuja vagueza não foi capaz de impedir a punição, bem como as manobras jurídicas e midiáticas realizadas em ambos os casos, representa uma ameaça ao Estado de Direito e à democracia em si. Este passa a ter um judiciário não mais amarrado ao mastro da Constituição, um Estado não mais constrito pelas regras constitucionais, mas uma maleabilidade maléfica da Carta Magna, utilizada para propósitos manipulativos pelas instâncias do poder (SALGADO, 2018).

Ao tratar, portanto, do lawfare no Brasil e na Argentina, especificamente nos casos em que as mulheres que se encontravam em cargos políticos foram vítimas desse instituto, é possível perceber a violência de gênero que se apresenta então no meio político: a não aceitação, por exemplo, da palavra "presidenta" no vocabulário - tanto no caso argentino, quanto no brasileiro -, a representação midiática das ex-presidentas como "loucas" e "incapazes" de estar no meio político (RECHETNICOU e VIEIRA, 2017), são apenas exemplos dos estereótipos ainda remanescentes de um sexismo que afasta as mulheres da política, de modo a prejudicar, em muito, a representatividade política de mais de $50 \%$ da população, seja no Brasil (INSTITUTO BRASILEIRO DE GEOGRAFIA E ESTATÍSTICA, 2010), seja na Argentina (INSTITUTO NACIONAL DE ESTADÍSTICA Y CENSOS, 2010).

O que se pode anotar, deste modo, é que a manipulação dos institutos jurídicos no lawfare, quando voltada a mulheres, assume ainda uma 
nova força: a da violência de gênero; se manifesta e se coloca não apenas a partir do uso do judiciário, mas também a partir e com base em estereótipos de gênero capazes de reforçar a aparente legitimidade, que passa a contar também com o apoio popular (vale lembrar que os escândalos jurídicos são amplamente utilizados nas instâncias do lawfare), do afastamento dessas mulheres do poder.

Cabe apontar que, nos processos aqui analisados contra ambas as ex-mandatárias, existem semelhanças e diferenças. Como ponto em comum, ambas eram líderes políticas com uma ampla base popular, e os meios opositores se dedicaram a minar esse apoio. No entanto, o caso Dilma difere de CFK, uma vez que a persecução contra a ex-presidenta brasileira foi de tal magnitude que chegou à instância do impeachment e sua consequente destituição do cargo, enquanto que, no caso argentino, o lawfare permanece na esfera de múltiplas causas judiciais, ainda sem resolução definitiva.

Neste sentido, a análise realizada neste artigo, ao tomar a violência de gênero e o lawfare enquanto lentes, ou eixos, para a comparação entre os casos brasileiro e argentino quando se trata das ex-presidentas Dilma Rousseff e Cristina Fernández de Kirchner, pôde encontrar, além da ameaça representada pelo lanfare ao Estado de Direito, já mencionado, a violência de gênero que se perpetua também no meio político, observando que pode ser - e, nos casos apresentados, foi - instrumentalizada pelo lawfare, com o intuito de obter apoio popular às manobras realizadas. Mais do que isso, essas possibilidade e efetividade, verificadas em ambos os casos, do uso dos estereótipos sexistas quanto às mulheres na vida pública demonstra que, embora tenhamos avançado, a representação política das mulheres ainda encontra obstáculos importantes a serem vencidos.

\section{Referências}

ARGENTINA. Lei no .871 , de 10 de fevereiro de 2012 .

ARGENTINA. Lei n 13.010, de 09 de setembro de 1947.

ARGENTINA. Lei 끈 24.012, de 29 de novembro de 1991.

ARGENTINA. Lei ñ 27.412, de 22 de novembro de 2017.

ARGENTINA. Lei nº 26.522, de 10 de outubro de 2009. 
AVELAR, Lúcia; RANGEL, Patrícia. Como as mulheres se representam na política? Os casos de Argentina e Brasil. In: BLAY, Eva Alterman; AVELAR, Lúcia. 50 Anos de Feminismo: Argentina, Brasil e Chile. São Paulo: Edusp, 2017, p. 255-299.

BENEVIDES, Silvio César; PASSOS, Ana Quele da Silva; SILVA, Maurício Ferreira da. Impeachment ou golpe? Análise do processo de destituição de Dilma Rousseff e dos desdobramentos para a democracia brasileira. In: Congreso Latino-Americano de Ciência Política, 9., 2017, Montevidéu. Montevidéu: Alacip, 2017. Disponível em: <http://www.congresoalacip2017. org >. Acesso em: 10 abr. 2019.

BISHARAT, George. Law Against the People/The Empire Strikes Back. Revista Antropolítica, Niterói, v. 107, n. 54, p.296-308, fev. 2017. Semestral. Tradução livre. Disponível em: < https://repository.uchastings.edu/cgi/viewcontent.cgi? article $=2635 \&$ context $=$ faculty_scholarship $>$. Acesso em: 05 abr. 2018.

BRASIL. Lei no 9.540, de 30 de setembro de 1997.

CARLSON, John; YEOMANS, Neville. Whither Goeth the Law: Humanity or Barbarity. In: CROSSLEY, David; SMITH, Margareth. The Way Out: Radical Alternatives in Australia. Melbourne: Lansdowne Press, 1975. Disponível em: <http://www.laceweb.org.au/whi.htm>. Acesso em: 04 abr. 2019.

CENTRO DE INFORMACIÓN JUDICIAL (CIJ). Cristina Fernandez de Kirchner. Disponível em: https://www.cij.gov.ar/buscador.html?acc=search\&pagina $=6 \& f e c h a \_i n i=\& f e c h a \_i n i \_a u x=\& f e c h a \_f i n=\& f e c h a \_f i n \_a u x=\&-$ search $=$ cristina + fernandez + . Acesso em: 29 abr. 2019.

CENTRO DE INFORMACIÓN JUDICIAL (CIJ). La Corte Suprema declaró la constitucionalidad de la Ley de Medios (2013). Disponible en: $<$ https://www.cij.gov.ar/nota-12394-La-Corte-Suprema-declar--la-constitucionalidad-de-la-Ley-de-Medios.html> Último acceso: 30 abr. 2019.

CHATES, Tatiane de Jesus. Algumas Versões do Impeachment. In: Anais Eletrônicos Seminário Internacional Fazendo Gênero 11 \& 13th Women's Worlds Congress: Transformações, Conexões, Deslocamentos. Florianópolis, 2017. Disponível em: <http://www.wwc2017.eventos.dype. com.br/site/anaiscomplementares>. Acesso em: 10 abr. 2019.

COMAROFF, Jean; COMAROFF, John. Law \& Disorder in the Postcolony. Chicago: University of Chicago Press, 2006. 
CRISTINA KIRCHNER denunció persecución judicial, Va con firma Mendoza. 14 ago. 2018. Disponível em http://vaconfirmamendoza.com.ar/?articulos/id_6018/cristina-kirchner-denuncio-persecucion-judicial. Acesso em: 30 abr. 2019

CRISTINA KIRCHNER, otra vez procesada. Pagina 12. 18 mar. 2019. Disponível em: https:/ /www.pagina12.com.ar/181831-cristina-kirchner-otra-vez-procesada. Acesso em: 30 abr. 2019.

CRISTINA se burló de Bonadio y de Clarín por intentar tapar los tarifazos de Macri: “Una Obra de arte es esta tapa”, Info 135: Información y Politica Bonaerense. 28 dez. 2018. Disponível em: https://info135.com. ar/2018/12/28/cristina-se-burlo-de-bonadio-y-de-clarin-por-intentar-tapar-los-tarifazos-de-macri-una-obra-de-arte-es-esta-tapa/. Acesso em 30 abr. 2019

D’ADAMO, Orlando et al. Mujeres candidatas: percepción pública del liderazgo femenino. Revista de Psicología Social, v. 23, n. 1, p.91-104, jan. 2008. Informa UK Limited. http://dx.doi.org/10.1174/021347408783399534. 27 abr. 2019

DIRECCIÓN NACIONAL ELECTORAL, MINISTERIO DEL INTERIOR, OBRAS PÚBLICA Y VIVIENDA. Resultado Elecciones Nacionales: Elecciones 2011. Disponível em: https://www.argentina.gob.ar/interior/dine/resultadosyestadisticas/2011\#5. Acesso em: 29 abr. 2019.

DUNLAP JUNIOR, Charles J. Lawfare Today: A Perspective. Yale Journal Of International Affairs, New Haven, v. 1, n. 1, p.146-154, nov. 2008. Disponível em: <https://scholarship.law.duke.edu/cgi/viewcontent.cgi?referer=https: / scholar.google.com.br $/ \&$ httpsredir $=1$ \&article $=5892 \&$ context $=$ faculty_scholarship $>$. Acesso em: 05 abr. 2019.

FERNÁNDEZ DE KIRCHNER, Cristina. Sinceramente. 1 era edición. Ciudad Autónoma de Buenos Aires, Argentina. Ed. Sudamericana. 09 maio 2019.

HELMKE, Gretchen; WOLFSON, Leandro. La lógica de la defección estratégica: relaciones entre la Corte Suprema y el Poder Ejecutivo en la Argentina en los períodos de la dictadura y la democracia. Desarrollo Económico, Vol. 43, No. 170 (Jul. - Sep., 2003), p. 179-201.

INSTITUTO BRASILEIRO DE GEOGRAFIA E ESTATÍSTICA. População Residente por Sexo. 2010. Disponível em: https://www.ibge.gov. br/estatisticas/sociais/populacao/9662-censo-demografico-2010.html?edi$\mathrm{cao}=9673 \& \mathrm{t}=$ destaques. Acesso em: 30 abr. 2019. 


\section{INSTITUTO NACIONAL DE ESTADÍSTICA Y CENSOS. Censo}

Nacional de Población, Hogares y Viviendas 2010. 2010. Disponível em: https://www.indec.gob.ar/censos_total_pais.asp?id_tema_1=2\&id_ tema_2=41\&id_tema_3=135\&t=3\&s=0\&c=2010. Acesso em: 30 abr. 2019.

MARTIN, Xavier. Misogynie des rédacteurs du Code civil: une tentative d'explication. Droits: Revue française de Théorie, de Philosophie et de Culture juridiques, Paris, v. 41, n. 1, p.69-89, jan. 2005.

MENEZES, Eduarda Lattanzi. Governo Dilma a partir da perspectiva de gênero nos âmbitos internacional e doméstico. In: Congreso Latino-Americano de Ciência Política, 9, 2017, Montevidéu. Montevidéu: Alacip, 2017. Disponível em: <http://www.congresoalacip2017.org>. Acesso em: 10 abr. 2019. MIGUEL, Luis Felipe. Gênero e representação política. In: MIGUEL, Luís Felipe; BIROLI, Flávia. Feminismo e Política: uma introdução. São Paulo: Boitempo, 2014, p. 93-107.

MORENO, Guillermo Raúl. El Poder Judicial como arma política. Sobre la intervención judicial del partido justicialista en la República Argentina.

ReDeA: Derechos en acción, S.l., v. 3, n. 7, p.387-400, jul. 2018. Disponível em: <http://sedici.unlp.edu.ar/handle/10915/68666>. Acesso em: 28 abr. 2019.

OBSERVATORIO POLÍTICO ELECTORAL, MINISTERIO DEL INTERIOR, OBRAS PÚBLICA Y VIVIENDA. Participación de mujeres en el Congreso Nacional 2017-2019. 2019. Disponível em: $<$ https://www. argentina.gob.ar/interior/observatorioelectoral/analisis/mujeres $>$. Acesso em: 28 abr. 2019

PHILLIPS, Anne. Which Equalities matter? Londres: Polity, 1991.

PRESIDENTA se escribe con a, La Nación. 5 nov. 2007. Disponível em: <https://www.lanacion.com.ar/opinion/presidenta-se-escribe-con-a-nid959335> Acesso em: 28 abr. 2019.

PÉREZ, Sara Isabel; AYMÁ, Ana Maria.(ESCREVER OS NOMES PRÓPRIOS POR EXTENSO.) MEDIOS, MULTIMODALIDAD, GÉNERO Y POLÍTICA: Cristina Fernández de Kirchner en Noticias. Revista Observatório, v. 3, n. 6, p. 517-556, 1 out. 2017.

RECHETNICOU, Amanda Oliveira; VIEIRA, Viviane C. Gênero, Política e Mídia: uma análise da representação e identificação de Dilma Rousseff no ano de 2016. In: Anais Eletrônicos Seminário Internacional Fazendo Gênero 11 \& 13th Women's Worlds Congress: Transformações, Conexões, Deslocamentos. Florianópolis, 2017. Disponível em: < http://www.wwc2017. eventos.dype.com.br/site/anaiscomplementares>. Acesso em: 10 abr. 2019. 
SALGADO, Eneida Desiree. Populismo judicial, moralismo e o desprezo à Constituição: a democracia entre velhos e novos inimigos. Revista Brasileira de Estudos Políticos, Belo Horizonte, v. 1, n. 117, p.193-217, dez. 2018.

SARNEY, José. Presidenta ou presidente. Diário da Manhã. Goiás. 19 nov. 2010. Disponível em: <http://www.academia.org.br/artigos/presidenta-ou-presidente>. Acesso em: 29 abr. 2019.

SILVA, Adriana Campos; SANTOS, Polianna Pereira dos. Participação política feminina e a regulamentação legal das cotas de gênero no Brasil: Breve análise das eleições havidas entre 1990 e 2014, p. 427-448. In: XXIV Congresso Nacional do CONPEDI, 2015, Belo Horizonte. Teorias da Democracia e Direitos Políticos. Florianópolis: CONPEDI, 2015.

SIQUEIRA NETO, José Francisco. Delação, notícia de jornal, condenação: Elementar, meu caro Watson! In: PRONER, Carol et al. Comentários a uma Sentença Anunciada: o processo Lula. Bauru: Canal 6 Editora, 2017. p. 223-227.

TOPPI, Hernán Pablo. Políticas públicas y derechos políticos: Del voto femenino a las cuotas de género como respuesta a los problemas de representación política de las mujeres en la Argentina. Perspectivas de Políticas Públicas. vol. 5 (n 10), p 87-120, 2016.

TRIBUNAL SUPERIOR ELEITORAL. Estatísticas eleitorais 2014: Estatísticas de resultados. Disponível em: <http://www.tse.jus.br/eleitor-e-eleicoes/estatisticas/eleicoes/eleicoes-anteriores/estatisticas-candidaturas-2014/ estatisticas-eleitorais-2014-resultados>. Acesso em: 04 abr. 2019.

VIOTTTI, Maria Luiza Ribeiro. Declaração e Plataforma de Ação da IV Conferência Mundial Sobre a Mulher. Pequim, 1995. Disponível em: $<$ http://www.unfpa.org.br/Arquivos/declaracao_beijing.pdf>. Acesso em: 15 mar. 2018.

Indiana Rocío Azar - Graduada em Ciência Política pela Universidad de Buenos Aires. Mestranda em Sociología Política Internacional na Universidad Nacional de Tres de Febrero - Argentina. E-mail: azar.indiana@gmail.com.

Luiza Tavares da Motta - Graduada em Direito pela Universidade Federal do Paraná. Inscrita no Master 1 Droit du Patrimoine na Université de Poitiers - França. E-mail: luiza. tavaresmotta@outlook.com. 
